\title{
Inpatient building design analysis of comprehensive hospital
}

\author{
Gao Jing \\ (Kunming University of Science and Technology Design \& Research Institute, Kunming, Zip code \\ 650051)
}

KEYWORD: Hospital inpatient department, Medical model, Social disease spectrum, Hospital construction standards, National health ideas

\begin{abstract}
This paper in view of the architectural design of hospital inpatient department, has carried on the analysis from various aspects factor changes of medical model of historical development, social environment, national policy, the philosophy of nursing progress, society of spectrum of disease and medical equipment and medical technology development, sort out the different factors that influence on hospital inpatient department building design, summarize the hospital needs inpatient department of architectural design, has a certain role in guiding the design of this kind of architecture in the future.
\end{abstract}

\section{Introduction}

The inpatient department is one of the main contents of hospital buildings, mainly to meet the needs of the sick inpatient rehabilitation needs, also has other functions, functions such as operation, training, conference, clinical research, office etc.. Hospital often encounter problems, reconstruction, expansion in the new development of modern comprehensive hospital, has the characteristics of high complexity and internal streamline function. Modern general hospital building usually contains the following functional units: general nursing unit, ICU (intensive care unit), operation Department, office, classroom and conference room. The relationship between architecture and environment in hospital department and human life closely, so by the various countries in the world pay attention to. Medical information network and rapid development of the hospital intelligent and global coverage, great breakthrough the limitation of time and the original pattern of medical. The revolution of science and technology will be in today's society advance from industrial society to information society, has provided the powerful support for the development of science and technology for the development of medical technology. High-tech medical equipment has played a significant role in the diagnosis and treatment of diseases and judgment, the update cycle is shortened gradually, it also puts forward new requirements for medical building: the need for flexibility and reasonableness of the use of space would have to meet the application and update technology and equipment of the. The technical progress also has exerted profound influence on people's medical treatment mode. So it is necessary for the influence factors of the inpatient department building design were analyzed, in order to guide the design of the building.

\section{Evolution of medical model}

Since ancient times, human medical model has roughly gone through three stages: ancient religion medicine and the experience of the medical model; medical model of modern experimental medicine and machinery; several modern biomedical and overall medical model development stage. The development stage of each kind of medical mode, form of hospital buildings have their corresponding, hospital building has also experienced the development from the bud to modern hospital.

\section{Religion medicine and Experience medicine model}

Ancient people in the medical practice, rely on simple means to fight with the disease, the disease is attributed to ghosts, providing a suitable environment for medical and religious experience medicine. This period of medical institutions gradually formed, appeared the rudiment of early 
hospital. The show in the "along the river during the Qingming Festival" in the Northern Song Dynasty Dongjing (present-day Kaifeng) in the bustling street, there is a painted on clinic, pharmacy. This period "hospital" based on the experience medicine, medical level is very low, the quantity is less, can not form a truly has the medical scientific significance of the hospital.

\section{Experimental medicine and Mechanical medicine model}

With the development of science and technology, medical technology has made great progress, to sixteenth Century, the invention of the microscope will be more medical research gradually into the microscopic world from the macro guidance, and gradually into the molecular level. During this period the medical technology also appeared the unprecedented prosperity, for example: transfusion techniques, anesthetic technique, simple medical care have been made. London in the late nineteenth Century appeared in St. Thomsen's Hospital, will house six Nightingale type ward common department and the corridor connected, as a whole, is the nursing unit form earlier. During this period the medical profession is influenced by the industrial revolution, tend to use a machine to match the human body, the human body life phenomenon as the mechanical movement, the excessive worship of medical technology and medical equipment, hospital will be regarded as "workshop", the doctor is technician, patients like failure "machine", it is the connotation of machinery of the medical model, only pay attention to the neglect of human rationality and patients psychological feeling. During this period the hospital is not a simple charity, in medical technology, medical equipment, professional division of labor and cooperation have collective and modern hospital similar, reflected in the building is the discrete layout, building branch. The different uses of the hospital building personality tend to be more obvious.

\section{Modern biomedical and Holistic medicine model}

In the second half of the twentieth Century, people gradually realized that the relationship between the disease and human biological variables, the research results of psychological and behavioral science and sociology, the awareness about the disease and health is not limited to the physiology category. Statistics show that modern human disease and death: the psychological and social factors and human health and disease is of great relevance, physiology, psychology and sociology of the perfect state and social factors have positive relevance to human health. Modern biomedical comprehensive therapy, to create a good environment for the whole medical patients from psychology, sociology and environment, architecture etc.. Physiological, psychological experience so hospital building should be comprehensive study of patients, hospital by the medical original to "health care, medical, rehabilitation" type conversion. The hospital will pay more attention to human society, psychological needs, medical environment tend to be more family oriented, garden, art. To the patient as the center, the design principle in the bio - psycho - social medical model has become the dominant ideology under the guidance of modern hospital design.

Table 1. Evolution of medical model

\begin{tabular}{|c|c|c|c|}
\hline $\begin{array}{l}\text { Medical model } \\
\text { Experience }\end{array}$ & $\begin{array}{l}\text { Religion medicine } \\
\text { Experience medicine model }\end{array}$ & $\begin{array}{l}\text { Experimental Medicine } \\
\text { Mechanical medical model }\end{array}$ & $\begin{array}{l}\text { Modern biomedicine } \\
\text { Holistic medical model }\end{array}$ \\
\hline $\begin{array}{l}\text { Medical } \\
\text { characteristics }\end{array}$ & $\begin{array}{l}\text { Hospital has single function } \\
\begin{array}{l}\text { Temple, House, Institution, } \\
\text { charity }\end{array} \\
\text { Poor conditions }\end{array}$ & $\begin{array}{l}\text { Medical technology, medical } \\
\text { equipment, specialized division of labor } \\
\text { similar to the modern hospital } \\
\begin{array}{l}\text { Divided into building, Clinical } \\
\text { departments }\end{array} \\
\begin{array}{l}\text { Different uses of building personality } \\
\text { tend }\end{array}\end{array}$ & $\begin{array}{l}\text { Hospital pay more attention to people's } \\
\text { social and psychological needs } \\
\text { Medical environment tend to family, } \\
\text { courtyard, art, Architectural layout is } \\
\text { reasonable and orderly } \\
\text { Architectural character more obvious }\end{array}$ \\
\hline $\begin{array}{l}\text { Hospital } \\
\text { characteristics }\end{array}$ & $\begin{array}{l}\text { Medical experience is } \\
\text { limited, with simple means } \\
\text { to fight disease, the disease is } \\
\text { attributed toghosts, rely on the } \\
\text { experience } \\
\text { of medical practitioners, } \\
\text { superstition ghosts }\end{array}$ & $\begin{array}{l}\text { Understanding human life as a } \\
\text { mechanical movement, the worship of } \\
\text { medical technology and medical } \\
\text { equipment, pay attention to rational, } \\
\text { ignore the human nature and the } \\
\text { patients psychological feelings }\end{array}$ & $\begin{array}{l}\text { Understanding of disease and health is not } \\
\text { limited to the category of physiology } \\
\text { Emphasize comprehensive treatment, to } \\
\text { create a good overall medical environment } \\
\text { for patients }\end{array}$ \\
\hline
\end{tabular}




\section{Influence of the change of social environment and national policy on inpatient building}

\section{Economic and social development to promote the hospital construction progress}

With China's health system reform and the gradual perfection of socialist market economic system, as an important part of market economy in medical service market gradually establish, together with the national planning policy guidance, the allocation of health care resources regulatory role, thus strengthening the competition and differentiation of hospital. At the same time, continuously improve people's living standards, health consciousness strengthens unceasingly, has put forward higher requirements to the medical service.

The hospital construction, especially the comprehensive hospital construction level is closely related to the development of the national economy. With the reform of the national economy deeply, the development of the national economy the emergence of hitherto unknown momentum, city construction is developing at an astonishing speed, but also from the objective to promote the hospital construction pace of marching towards modernization. As an important part of hospital inpatient building has also changed greatly

\section{Changes in national standard and medical policy}

Based on China's "the sixth five year plan" and "the seventh five year plan" hospital construction summary, the state has formulated "general hospital construction standards". Enter after twenty-first Century, with the construction of the development of the cause of health and medical institutions are facing new challenges, in the infrastructure construction of the original standard summary and carries on the investigation to the present situation of the hospital, general hospital construction standards were revised, in order to guide comprehensive hospital better construction.

China hospital after the construction of nearly 40 years of arduous and tortuous, the overall scale and modernized level has greatly improved, medical treatment is difficult, the difficult problem of preliminary alleviate hospital. From 1950 to 198030 years, our hospital beds per thousand residents index from $0.147 \mathrm{bed} /$ thousand to thousand $1.94 \mathrm{bed} /$ American; over the same period from 11 per thousand to thousand bed bed 5.86/80; in Canada as a thousand 4.6 bed /, the Nordic countries of about one thousand people 5 bed /; 90 in Singapore, Taiwan, Hong Kong, the indexes are the thousands of thousands of people, $3.5 \mathrm{bed} / 4.3 \mathrm{bed}$ and $4.6 \mathrm{bed} / /$ a thousand people.

According to the momentum of development in our country now, the future is expected to reach 3 bed / thousand level, and the developed countries to the negative growth will be more close to the level of. According to the development of hospital beds the world situation and the basic situation of China's overpopulation, shortage of resources, the realization of the 3 bed / when thousands of people after the goal, development trend may become more stable. This means that the focus of our hospital building will be from the expansion of scale, beds, steering, and the optimization of hospital work efficiency and improve the quality of the environment.

\section{Changes in nursing philosophy of society and the advancement of the disease spectrum}

\section{Development of nursing philosophy}

With the development of medicine, nursing to become a modern and independent discipline, it from the medical auxiliary discipline is simple, the development of the biology, medicine and other natural science and psychology, ethics, sociology and other social science interdisciplinary comprehensive applied science. The development of nursing also brought nursing concepts and the new nursing mode, nursing management is more and more scientific, and constantly improves the quality of nursing and improves nursing efficiency. Therefore, the 


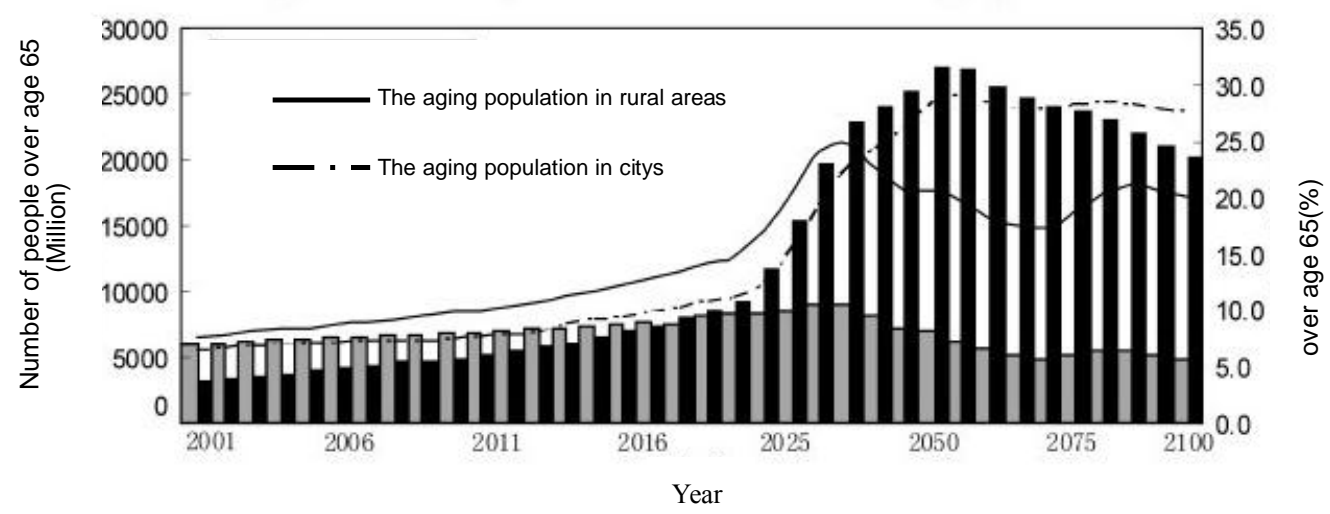

Figure 1. The trend of aging population in China

development of nursing of nursing unit composing mode also has an important impact.

Changes of nursing science, to the new requirements of inpatient department building design is proposed in this paper, the emergence of new approaches, such as the establishment of nurses in nursing station outside traditional angle, as time Nurses 'Station level, a division of the nursing unit into two or three smaller units, to reduce the number of patients in each unit service medical staff and patients, shorten the distance and improve the link between nurses and patients.

\section{Changes in population and social disease spectrum}

According to the definition of the dynamic analysis indicators, the world's population aging society (aging society) refers to the country's population of 65 people aged state of (a) aging rate reached $7 \%$. And according to the 2010 sixth national population census data bulletin, the mainland's 31 provinces, autonomous regions and municipalities directly under the central government and the population of a soldier in active military service, the population aged 60 and above accounted for $13.26 \%$, of which 65 years and older population accounted for $8.87 \%$, which means that our country has entered the aging society (figure 1.).

Our country of the population aging speed and the number of elderly people are never in the history of human society development, medical and health undertakings of our country will be put forward many subjects, produced great impact. Although still occupy the important position of the treatment of patients with severe diseases, but the geriatrics and called the adult chronic diseases, such as high blood pressure, diabetes, etc., also calls for the establishment and facilities that meet the needs of medical services. The change of the "disease" prejudicial to China's national health put forward new demands for hospital building and its public space.

With degree of population aging in our country, all kinds of senile chronic diseases will be more obvious growth. For this kind of disease diagnosis and treatment, to create a good medical environment, care about the environment of patients psychological experience, adjust the psychological balance in patients with medical treatment is very important.

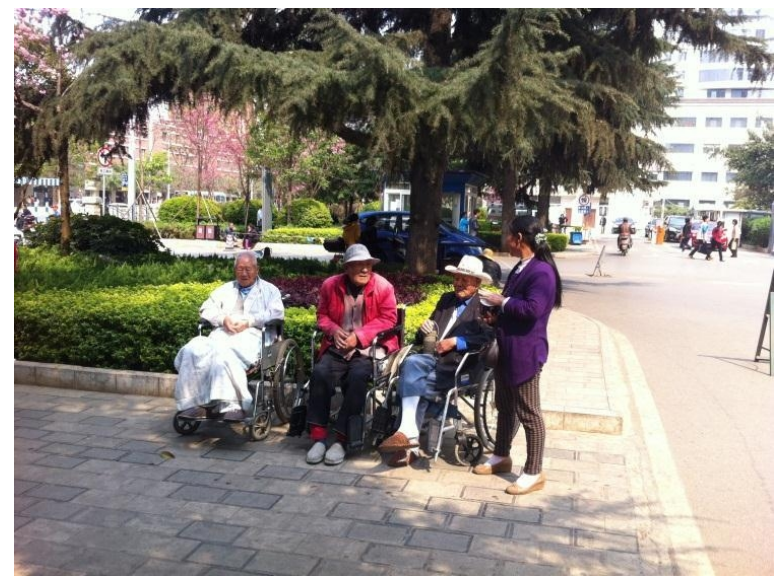

Figure2. Elderly patients in hospital 


\section{Progress of medical equipment and medical technology}

\section{Complication and diversification of medical equipment}

Hospital is a very professional, functional complex building type, rapid progress in medicine and new medical technology and the rapid development of medical equipment, hospital composition is also more and more tolerant technology. The other medical instruments and equipment upgrading soon, abroad the update period is about $3 \sim 5$ years, this requires that the hospital have the flexibility in the whole life cycle, so as to adapt to the special requirements. Especially because hospital construction investment, complicated functions, building if you can't adapt to this change, will cause problems to use. For ward building design, the introduction of a series of new equipment and new technology, such as computer networks, intercom system, monitoring system, etc., will be important influence on the ward building design, further promote ward to the direction of informatization, integration and development.

\section{Intelligence and information technology}

At present, and the rapid development of information technology, the application in all walks of life more and more widely, also made great progress in the application of the medical, a combination of intelligent building technology and intelligent hospital management and medical technology is a new type of intelligent hospital. Such as Hospital Information System

(Hospital Information System) of continuous development and improvement of various departments in the Hospital of the application is more and more importance, changing the traditional mode of Hospital medical treatment, diagnosis, management and so on, become a revolutionary factor in the development of the Hospital. Specific to the nursing unit, computer system for nursing practice, nursing records, nursing quality, nursing research, teaching, even has been a great help.

Information technology affects the function of hospital building layout and design requirements, especially the extensive use of computer network, communication equipment, and other various high-tech facilities, the construction layout, power supply, heating, air conditioning, fire control and structure design are completely different new requirements are put forward. Architectural design must meet the requirements of intelligent, good for building construction platform, otherwise will bring big trouble in use, can't even realize intelligent function. When building plane and profile design, you need to provide enough cable line space and add a variety of intelligent facilities dedicated room, at the same time also require functional room appropriate concentration, to ensure the effective use of facilities. In the structure design and the choice of wall materials, should cooperate with warm water, electricity and professional coordination, construction.

\section{Changes of national health ideas and requirements to the medical environment}

\section{Transformation of the national health ideas}

With the development of national economy, the improvement of people's living standards, the national medical needs are changing, from the original pure spa to medical health development, maintain life, and prolong life to improve the quality of life. So to the hospital environment, conditions and facilities with new and higher requirements. On the one hand, requires hospitals have related to health care, nutrition, health, rehabilitation, medical facilities, on the other hand for hospitals in hospital environment more comfortable and humanized, many patients want hospital inpatient environment facilities don't below household environment. Choose the hospital seeing a doctor phenomenon in the development, under the same technical level under the premise of good conditions, facilities good hospitals have a "full", whereas conditions corresponding almost hospital staffer, which from another aspect to promote the hospital construction to a higher level.(figure 3.) 


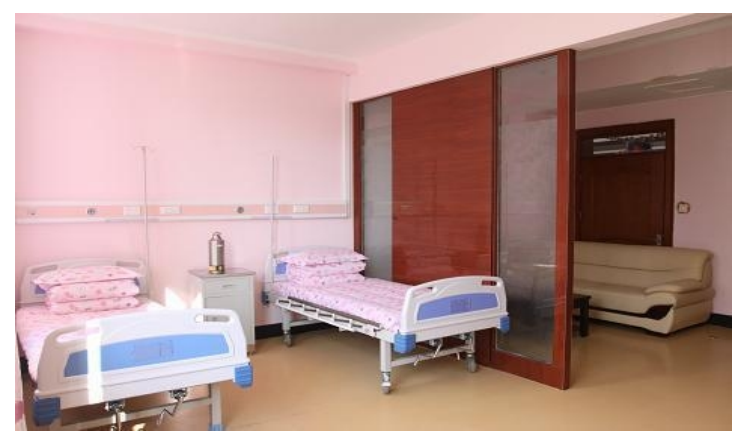

(a)

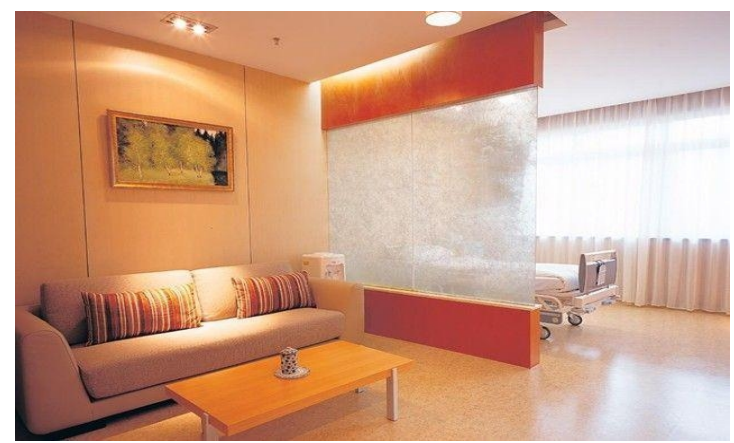

(b)

Figure 3. A China hospital VIP ward

\section{National attention to the medical environment}

People is closely related to the environment, when people sick, not only can't control the original environment, but also subject to the conditions of the medical staff and ward environment control, the mood will be affected, which in turn affect the process and effect of patients, and therefore requires comfortable good medical environment. To create a good medical environment is designed to make the patients can well adapt to the ward environment, including mental adaptation and the physiological adaptation, make its produce physiological and psychological sense of beauty, body and mind to get the corresponding content. Physical pleasure, is to meet the patients physiological needs, such as air, sunshine, convenient, comfortable, etc; Psychological sense of beauty is the need of a high level, is a uniquely human, is the spiritual needs are met, it as the spiritual activities, such as cognition, thought, evaluation, imagination, and to be able to continue to feel for a long time. Therefore, the current advanced hospital nursing unit, besides gives treatment nursing to the patients, how to make the patient in life, physiological and psychological feeling has obvious different with their normal life, has been widespread attention, for patients to create a comfortable, warm like family environment, has become a very important problem in the design of buildings. In addition to the influence of the physical environment, social environment is also important. In the hospital in-patient department, social environment mainly includes the attitude of doctors and nurses, the relationship between nurses and patients, patients and family contact, etc. Modern medicine also gradually realized that a good social environment for the treatment of patients with has a positive effect, so the hospital building design also need to be able to provide appropriate space to meet the needs of the patient's social communication.

\section{Patients and medical staff requirement}

Users of nursing unit of Inpatient building are doctors, nurses, hospital visits, care workers and support staff, but The greatest impact on the nursing unit function is mainly two types of user - that is, patients and nurses. For the patients, the nursing unit is the treatment, rehabilitation and living places, they require medical environment, clean, convenient, comfortable and safe. Requirements of patients for nursing unit is mainly suitable for privacy, which can provide a more quiet, do not have too much interference in the personal space; communication space of multi-level, on the one hand encourage patients to get out of bed activities can help to speed up the process of treatment and 
rehabilitation, promote, on the other hand, with the people close to communication patients to seek psychological comfort, eliminate the fear, the important ways to improve confidence in the treatment, the patients in the hospital is still to maintain social contacts; other patients also requires a certain autonomy, the traditional hospital management to limit more patients, too much emphasis on the medical treatment is convenient, but not given careful consideration from the view of social psychology patients. For the nurses, the nursing unit is their workplace. In the past, the nursing unit design is more consideration to improve nursing efficiency and shorten the nurses walk distance. With the development of society, the right to own the nurse put forward more requirements, thus to protect nurses work efficient, convenient, comfortable, reduce the intensity of work and other aspects of the request received widespread attention, including as much as possible to shorten the distance of nursing to improve nursing efficiency, logistics transport equipment automation, semi automation reduce the nursing intensity, improve the nurse with comfortable building decoration and furniture, architecture and interior design work environment.

Relationship between patient and nurse the patients should be given attention, because in the patient's condition, the desire of family members, medical care and attention, so it can provide a suitable space, make the patient feel easier to contact with the nurses, medical staff can see more activity in the sight of communication, feel them around in the side and the psychological sense of security, there is enough space to facilitate the communication in nursing, and patients in nursing station should contact more pleasant, make patients to eliminate the sense of isolation.

On the architectural design requirements, nurses and doctors, patients and visitors have different requirements for the nursing unit, meet their requirements on the one hand from the hospital management to adjust, on the other hand, the architectural design of nursing unit should be from the unit partition, public transportation arrangement, various rooms of various plane the room layout and area, room facilities, profile design, structure design and the overall decoration and design of the physical environment and the design level of careful consideration, to provide truly meet their requirements of good medical environment for users.(figure 4.)

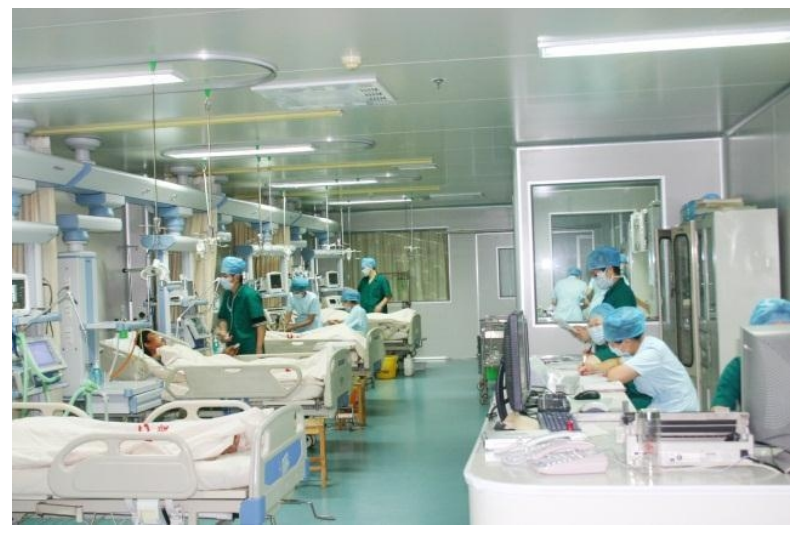

Figure 4. An Intensive care unit

\section{Requirement characteristics of ordinary patients}

The ordinary patient is mainly refers to the non-life threatening or in secondary nursing and rehabilitation nursing of the patients. These patients are sensitive over suspicious, for fear of relapse or exacerbation is often in a state of alert, mood fluctuations, fell outside the sound, light, heat and other stimulating ability, self-care confidence, dependence is strong, its demand is multifaceted. In general do not need to worry about the people in the life and worries, security, privacy, information, communication; entertainment has become a new hot spot in demand. Patients with painful scene scared to see the patient, but also do not want to put their own pain show and detrimental to their strong characters, so that the disease and not seek medical treatment "is a common psychological reactions of modern young patients, most of them want to temporarily quiet accomplishment. Patients had a rejection of emotion on the lack of privacy of public toilets with toilet, so the less popular bed ward. If the condition improved, patients like ambulation, recovery of function of patients with access to information, like communication, willing to help others, like television or entertainment, also often go to the garden green space activities. 


\section{Requirement characteristics of the elderly patients}

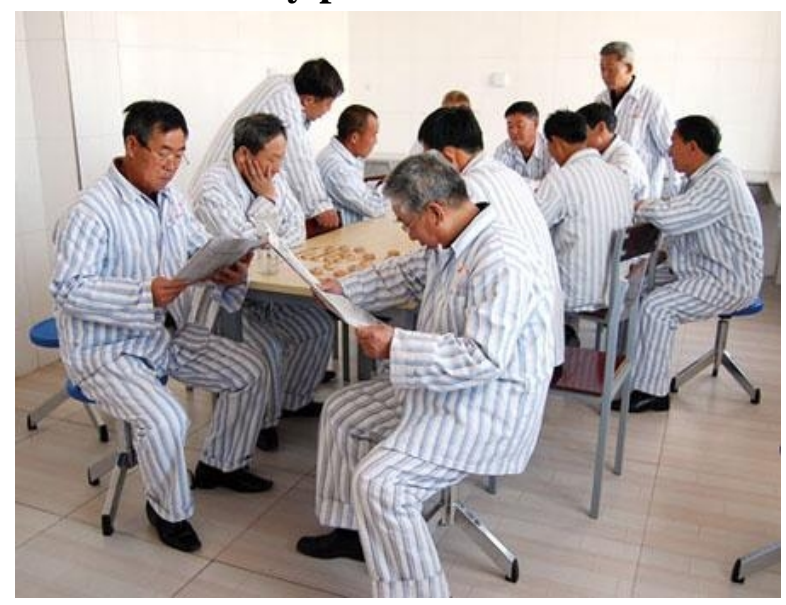

Figure 5. Reading and Chess Room

The elderly patients usually had career achievements, at home by his family and neighbors to respect. Once admitted to the hospital, try to follow the doctor's advice, listen to the nurse, sometimes difficult to adapt to the strong, and want to be respected. Want others to know his identity and achievement, respecting his wishes and habits. The old man is particularly afraid of loneliness; I hope to visit the sick in hospital nursing. The elderly patients are often childlike innocence reborn, performance of naive, like to play with the children. Hospitalized elderly gregarious, love relationships, there is nostalgic feelings, of the same age people have a natural affinity, often together reminiscences, enjoy opera, art exchange. Patients living environment should pay special attention to security, should not have indoor height, in order to avoid wrestling, and wheelchair accessible to avoid the use of light or mirror glass door, so as not to cause the illusion of space collision occurs. The elderly due to decreased visual acuity, all printed, signs, such as housing, font to large and bright, in order to facilitate the identification. For visually impaired people, should avoid direct sunlight and glare. The bathroom, channel should be considered to avoid sliding and install handrails.

\section{Requirement characteristics of children patients}

Children are the parents love at home, but they have to obey the hospital nursing management, thus easy to cause resentment. Children's nature is playful and active treatment in hospital, limiting their freedom of movement, especially afraid of injections and medicine, treatment of mandatory more disgusted, children leave their parents to a strange environment will feel lonely and sad, emotional control ability is very weak, isolation and family of children is more harmful than the disease itself, therefore, should allow parents to accompany the hospital, and increase. According to the experience of children's cognitive past, saw a white, white walls, white masks will associate the injection pain medication, bitter, resulting in "psychological reaction of the white terror". Psychologists study found that children love bright colors, can stimulate the happy mood, a lot of foreign children's ward, the ward corridor hung with color pictures, the animal model of blood specimens, children bed, hanging above the bed there are all kinds of toys (Figure 6.). Some hospital ward facilities such as toys, car, train, made the bed slipper style, color is also close to the children's ward of favorite foods such as egg yolk color, orange, green, and so on. Children's medical environment should be put in the medicine treatment combined with music, games and. Children's environment to Caution! Protection, prevent fall, slide, hit, hit, climbing balcony window, to prevent accidents. Children's condition changes a lot, their poor expression mainly rely on visual monitoring, so the spacing should be appropriate to increase the bed, so parents escort (Figure 7.). The game room should be conducive to the observation ward. Therefore, more emphasis should be placed on shortening the distance of nursing. 


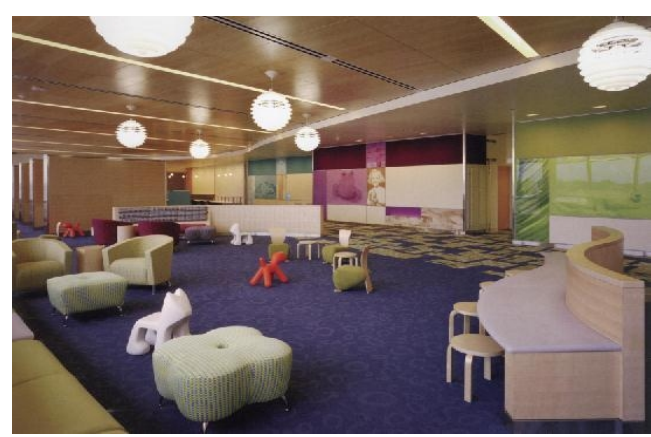

Figure 6. Children's activity room in hospital

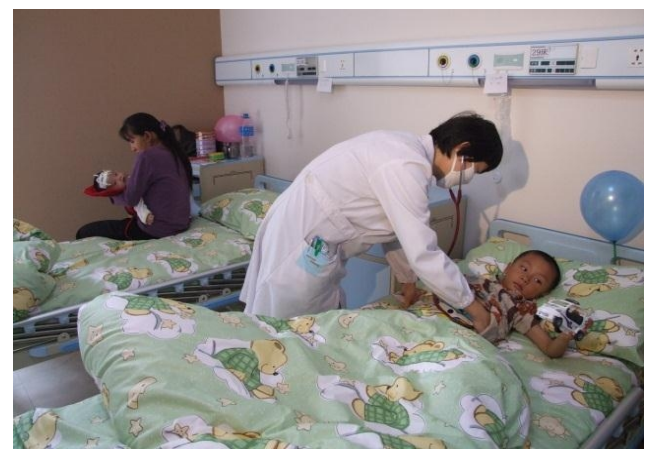

Figure 7. Children's ward in a China hospital

\section{Requirement characteristics of the medical staff}

The medical staff may be the most discerning user. Because of their working days are spent in the hospital environment, they spend most of their time in the inspection or stay in the office, they need to get rid of stress and fatigue, restore energy, and the effect of the architectural design in this process is very important, the medical care personnel also need good privacy, quiet the indoor space to rest. In the survey found, there are many medical staff said they want to get rid of the pressure and tension, and many ways for them to relax and some patients require hospital treatment contrary to, or is prohibited during the. The architectural design should be through the cover or space planning, interior space in the public ward building, create a lot of appropriate communication space. Nursing station should be located close to the ward, is conducive to the monitoring of patients; the shortest tour distance, so as to improve the work efficiency; the room color soft, coordination, moderate stimulation, so that the medical staff emotional stability, reduce their anxiety and fatigue, easy to work; work places should have some privacy, to avoid disturbing the crowded and noisy, have proper rest space, to stimulate the staff good psychological. China's "architectural and design code for general hospital" in the nursing station ward to the far distance should not be more than 30 meters, because more than 30 meters, it will undoubtedly increase the labor intensity of nurses, will also affect the efficiency of nursing staff. But with the requirements of the privacy of patients and ward environment improved, gradually separate ward into smaller groups, consisting of 8 or 6 open ward, now further into 3 people following the closed small ward, a direct result of this change is to greatly increase the routes of nurses, affecting the efficiency of nurses in intensive care the patients.

\section{Conclusion}

Based on the above analysis, the following factors have effect of comprehensive hospital building design:

(1) The change of medical model, the development of new biological - psychological - social model is the new requirement for hospital building construction;

(2) With China's health system reform and the socialist market economic system gradually improve, thereby strengthening the hospital competition and differentiation and improve people's living 
standard, to enhance the healthy health care consciousness, puts forward higher demands on medical services;

(3) The development of nursing science brings new nursing concept and mode, scientific nursing management also becomes increasingly, requirements to improve nursing efficiency, thus the development of the nursing of the nursing unit constitute model also has the important influence.

(4) The emergent events of public health and the progress of medical equipment and medical technology, intelligence and the introduction of information technology, hospital building construction needs to have stronger adaptability and flexibility, and can meet the needs of emergency, has rebuilt expansion and meet the needs of sustainable development.

\section{Reference}

[1] People's Republic of China Ministry of Health. (2008). "General Hospital construction standards." China Planning Press, Beijing.

[2] Wang Changtao.(2003), "The new trend of modern hospital architecture design in China." Architectural Journal, 2003(7),18-21.

[3] Wang Kai and Xu Fei.(2006). "Architecture style decided by agility--New trends of hospital building in USA and the challenge." Chinese Hospital,2006.10(2),23-28.

[4] Hou Changyin and Wang Yimeng.(2014). "The analysis on the modern hospital buildings synergetic development." Huazhang Architecture,2014.12,129-132 